\title{
An Innovative Integrated Learning Laboratory Environment
}

\author{
Ajay Mahajan and David McDonald \\ Lake Superior State University
}

\begin{abstract}
The current paradigm in engineering course instruction builds on a lecture prerequisite structure but ignores the need for a laboratory prerequisite structure. Educational quality is therefore diminished as instructors optimize specific laboratories but fail to optimize the overall program laboratory experience. This paper presents a learning environment that forces students to use not only concepts and skills but also actual data and models from lower division laboratories in upper division laboratories. The integration occurs because students must utilize their previous laboratory work as a reference as they study the different facets of the same experimental set-ups in multiple engineering laboratories. The students learn to appreciate the integrated nature of modern systems since they get to use the same set-ups in multiple courses. There are other indirect advantages of this approach in terms of financial economy and faculty professional development.
\end{abstract}

\section{Introduction}

For almost thirty years LSSU offered quality programs in engineering technology. In 1994, based on the input from alumni, employers of graduates, and members of the Industrial Advisory Board (IAB), a decision was made to switch from engineering technology to engineering. In 1996, after a two year process, the School offered Mechanical and Electrical Engineering degrees in place of the old technology degrees. A comprehensive transition plan was developed for students who were enrolled for technology degrees and wanted to obtain the new degrees in Mechanical or Electrical Engineering. The School was renamed the School of Engineering and Mathematics. The Technology Programs have always been TAC/ABET accredited, and the School is now aiming for EAC/ABET accreditation for its new engineering programs in the year 2000 under the new EAC Criterion 2000.

With the transition to engineering programs the School is trying to expand its horizons and explore new directions. One of these directions is the development of an applied research program, and it has lead to the development of a new facility called the Autonomous Systems Laboratory (ASL) that serves as a center for research and innovative curriculum development [1]. A second direction is the proposed development of a new laboratory called the Integrated Systems Engineering Laboratory (ISEL) that emphasizes the vertical integration of knowledge by forming a pre-requisite structure in laboratory work that spans across multiple courses. It will be shown that this new laboratory will cause a paradigm shift in student learning by moving from an isolated learning environment to an integrated learning environment. 


\section{The Problem}

The School's mission has always been to provide a quality education and prepare its students for industry by emphasizing hands-on experiences in the laboratories. The transition to engineering has required the School to offer new upper level courses that need new laboratories. The School has limited resources in terms of space and equipment, hence there is an immediate need for a solution to this problem.

\section{The Proposed Solution}

The authors have proposed the development of a multipurpose laboratory facility that will be used for undergraduate laboratories for multiple courses. Some of the courses that this laboratory will be used for are Dynamics, Machine Design, Vibrations, Automatic Control, Digital Control, Digital Signal Processing. All the six courses are envisioned to have a laboratory set-up, and currently only three of these courses have a laboratory component to them under the old engineering technology's scheme of things. Even if one were to modify the existing three laboratories for the new set-ups, it still leaves the School short three laboratories. This paper presents a novel scheme that entails setting up six independent experimental set-ups in the new laboratory facility called the Integrated Systems Engineering Laboratory (ISEL) that will be used by all of these six courses. Each of the courses will use the same six set-ups but study different facets of it. For example, one set-up will be an inverted pendulum experiment that has a rod balanced on a platform that moves in the horizontal plane. The aim is to move the platform using sensory feedback so as to balance the rod vertically. It is similar to a person trying to balance a stick vertically on the end of one's finger by moving the hand around. The following list shows the different facets that will be studied by the students in the six courses:

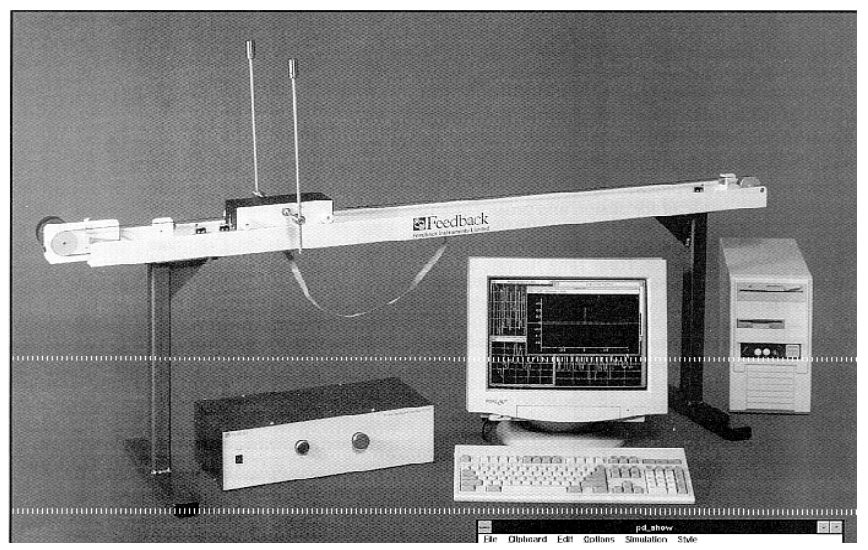

Dynamics: $\quad$ The system model, and its verification

Machine Design: The design of the physical model and selection of the components

Vibrations: The effect of vibrations and disturbances on the control scheme

Automatic control: PID control and the effect of change in parameters

Digital Control: Data-acquisition and digital domain study

DSP:

Sensor signal conditioning and digital filters

Five set-ups, similar in concept to the inverted pendulum, will allow for six different courses to have the same physical laboratory set-up. 
There is also another significant advantage, and that is that students do not need to spend unnecessary time on issues that do not pertain to that course. For example, students in Vibrations do not need to model the system from scratch, because they have already done so in Dynamics which is a prerequisite for Vibrations. Similarly, students in DSP have already studied the dataacquisition part of the set-up in Digital Control, and do not need to waste time in understanding the data-acquisition hardware and software. Five additional set-ups will be developed that are similar in concept to the inverted pendulum and represent truly integrated systems. An initial attempt has been made to identify these set-ups (some of these may change with time), and these are:

1. An inverted pendulum (will be bought from Feedback, Inc. [2]).

2. A MIMO helicopter (will be bought from Feedback, Inc. [2]).

3. A mobile robot (will be bought from TRC, Inc. [3]).

4. Forced and damped vibration set-up (will be bought from Cussons, Inc. [4]).

5. A motion control unit (has already been obtained from Delta Tau Data Systems, Inc. [5]).

6. An eccentric loading unit (will be developed in house).

\section{Integrated Learning Environment}

The new laboratory will use an Integrated Learning Environment model that involves a paradigm shift in the design of laboratory instruction. Typically, laboratory instruction suffers from isolated learning which results from a focus on short term solutions instead of long range goals. In the Isolated Learning model, the instructor develops laboratory exercises, experiments, and student materials based upon the immediate demands of a specific course. This results in optimizing the instruction in one course without regard to other laboratory courses.

The Integrated Learning Environment approach redefines the way laboratory instruction is designed. The integrated approach enables instructors to focus on long term goals while developing laboratory materials because the same multipurpose equipment set-ups are used for part or all of the laboratory instruction in sequential courses. This approach is demonstrated in the following figure.

The vertical or y-axis represents improvement in: (1) student learning, (2) faculty development,

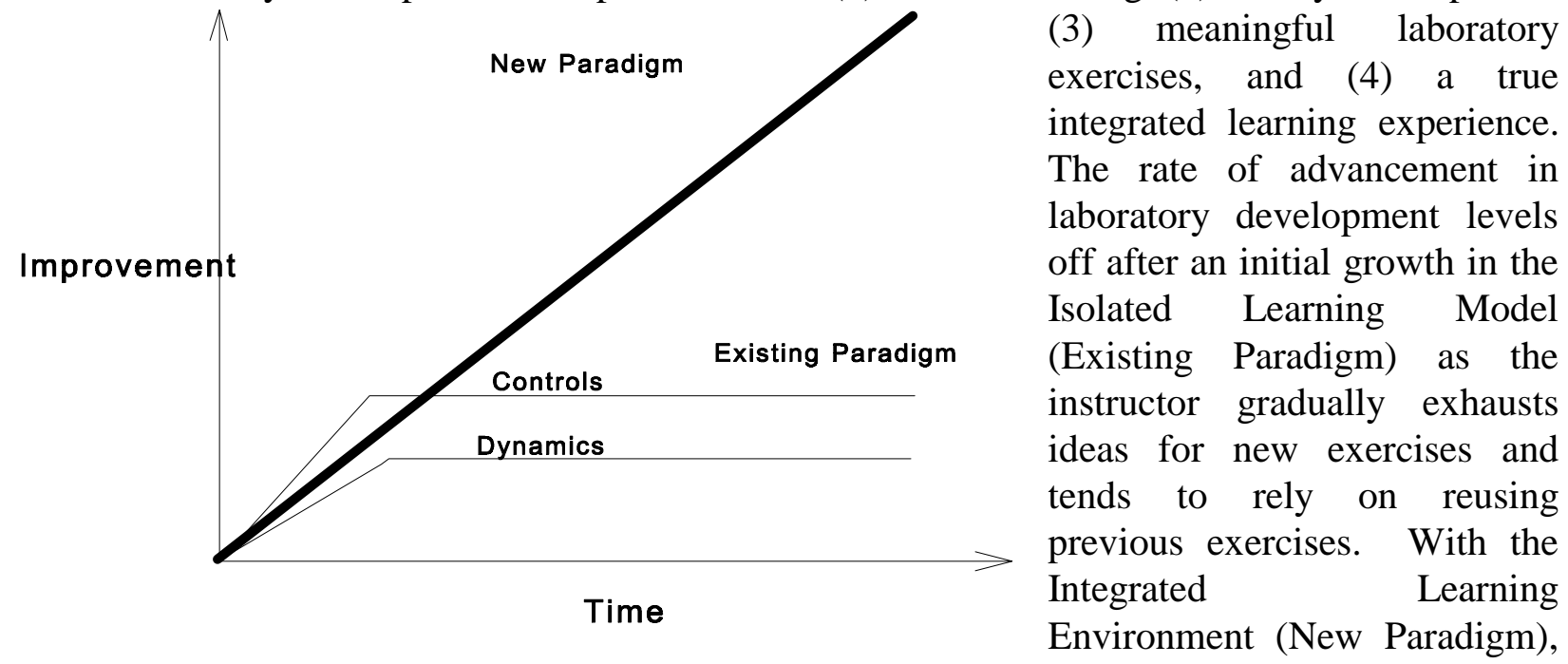


the student is forced to review and understand concepts and specific calculations from a prior course laboratory, and then apply that knowledge in the current course and future course laboratories. The new paradigm also encourages faculty to continuously upgrade their laboratory exercises and constantly keep in touch with other faculty members who are teaching other course laboratories within this integrated environment.

\section{Equipment On Hand and Pilot Work}

The School already owns the motion control set-up, and will build the eccentric loading test setup. Work on this project already exists in the form of some limited exercises in dynamics, automatic controls and digital signal processing, and the authors are working on the integration of these exercises to create the vertical learning environment. The School recently obtained a Tau Delta motion control unit which is the only existing experimental set-up that truly integrates dynamics and automatic controls. The rest of the equipment is being requested through grants submitted to the National Science Foundation.

\section{Conclusions}

This paper presents an innovative multipurpose laboratory environment that aims at integrating learning for students. The focus of this work is the vertical integration of knowledge in specific electrical and mechanical engineering courses. The truly innovative aspect of the proposed laboratory environment is that students use the same experimental set-ups in multiple courses, and build upon not only the work done in the previous laboratories of the same course, but also those of previous courses. This leads to a definite pre-requisite structure for the laboratory component of the courses similar to the courses themselves. Further, this approach is conducive to financial economy, faculty professional development, and encourages faculty members to work together to create meaningful experiments for students.

\section{Acknowledgments}

The authors would like to thank Dean Ray Adams for supporting this work as well as Prof. Maurice Walworth for his contribution to the vision of the Integrated Systems Engineering Laboratory at LSSU. 


\section{References}

[1] Lake Superior State University 1996-98 Catalog/Calendar, p 146.

[2] Feedback Incorporated, 437 Dimmocks Mill Road, PO Box 400, Hillsborough, NC 27278.

[3] Transitions Research Corporation, 15 Great pasture Road, Danbury, CT 06810.

[4] TecEquipment Incorporated, Box 1074, Acton, MA 01720.

[5] Delta Tau Systems, Inc., 9036 Winnetka Avenue, Northridge, CA 91324.

Ajay Mahajan is an Assistant Professor in the Department of Mechanical Engineering at Lake Superior State University. He received his Ph.D. Degree from Tulane University, New Orleans, in 1994. His research interests include robotics, controls, intelligent sensors, automated vehicles, and machine learning. He is a member of ASME, ASEE, IFAC, and SME. He is the Director of a new research facility called the Autonomous Systems Laboratory (ASL) at Lake Superior State University.

David McDonald is a Professor and the Chair of the Electrical Engineering Technology Department at Lake Superior State University. He received BSEE (1969) and MSEE (1971) degrees from Michigan Technological University. He is a registered professional engineer in Michigan, and an active member of ASEE, IEEE, and ISA. His technical interests focus on power conversion, intelligent motion control, and data acquisition and instrumentation systems. His teaching interests include techniques to enhance teaching effectiveness, and strategies that influence the recruitment and persistence of technical students. 